\title{
Investigation of Static, Modal and Harmonic vibration analyses of Single Row SKF6205 Deep Groove Ball Bearing for thermal applications
}

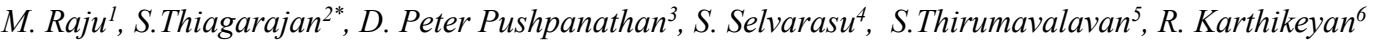 \\ 1,2,3 Department of Mechanical Engineering, Easwari Engineering College, Ramapuram, Chennai, India \\ ${ }^{4,5}$ Department of Mechanical Engineering, Arunai Engineering College, Thiruvannamalai, India, \\ ${ }^{6}$ Department of Mechanical Engineering, Gokaraju Rangaraju Institute of Engineering and Technology, Hyderabad, India
}

\begin{abstract}
It is the necessary to predict the endurance capability of the mechanical element with its increased application and complexity. The present research work estimates the stress variation and displacement characteristics using finite element analyses of Single Row SKF6205 Deep Groove Ball Bearing under radial and axial loadings. The vibration analyses are evaluated in three aspects; static, modal, and harmonic analysis. The simulations show the variation of stress levels of the bearing in different loads. These results are used to predict the fatigue life, wear rate, and productivity of the ball bearing at various stochastic conditions.
\end{abstract}

\section{Introduction}

The ball bearing is one of the essential components for any machine to rotate or to do its performance. So it is an essential consideration to do structural analysis. This paper discusses vibration analysis in all of its forms, including modal, harmonic, and static. It describes how balanced fault-free ball bearings vibrate. The restoring force of each ball in the load zone is calculated by Hertzian contact theory as,

$$
F_{i}=K \delta_{i}^{n}
$$

Where $\mathrm{K}$ is known to be stiffness and $\delta_{i}^{n}$ is the radial deformation. The expression for the radial deformation is given by [2],

$$
\delta_{i}^{n}=x \cos \left(\omega t+\frac{2 \pi i}{N}\right)+y \sin \left(\omega t+\frac{2 \pi i}{N}\right)-e
$$

It gives a detailed study on greases contaminated with particles of different sizes and hardness that are tested to shed new light [3]. There are two types of material used for the manufacturing of the bearings such as polyetheretherketone (PEEK) and polytetrafluoroethylene (PTFE). The inference obtained is that the polyetheretherketone gives a low vibration. The expression for calculating the coefficient of friction is given by

$$
\mu=\left(\frac{F^{*} R}{L^{*} r}\right)
$$

Where $\mathrm{F}$ is the force acting on the load cell, $\mathrm{L}$ is the axial load, $\mathrm{R}$ is the distance between the centers of the load cell and the bearing and $\mathrm{r}$ is the distance between the centers of the ball and the bearing [4]. It gives the maximum contact forces on

\footnotetext{
*Corresponding author: thiagarajan.s@eec.srmrmp.edu.in
}

the rolling element, which is done by the in-house developed program and detailed finite element analysis of the contact between the ball and the raceway. The force is given by,

$$
\sum_{t=1}^{n} q_{t}=F
$$

Illustrates the active magnetic bearing supported rotor as misaligned cage-less backup bearings. The elasticity of the rotor is modeled by the finite element method and the degree of freedom is expressed using the component mode synthesis [5]. The contact forces affecting the ball is obtained by,

$$
F_{i}=K_{c}^{t o t}\left(\delta_{i}^{t o t}\right)^{3 / 2}
$$

The total stiffness coefficient,

$$
K_{c}^{\text {tot }}=\left(\left(\frac{1}{K_{c}^{\text {in }}}\right)^{2 / 3}+\left(\frac{1}{K_{c}^{\text {out }}}\right)^{2 / 3}\right)^{-3 / 2}
$$

, implies the updating of rotors supported on ball bearings by inverse Eigen sensitivity method [6, 11]. It is used to identity bearing stiffness, damping, and shaft material damping parameters. The correlation is determined by the Modal Assurance Criterion method, by the expression,

$$
M A C=\frac{\left(\phi_{F E}^{i H} \phi_{X}^{j}\right)^{2}}{\left(\phi_{F E}^{i H} \phi_{F E}^{j}\right)\left(\phi_{X}^{i H} \phi_{X}^{J}\right)}
$$

The modeling of angular contact ball bearings and axial displacements for high-speed spindles equipped with angular contact ball bearings [7-10] are predicted. The centrifugal forces acting on bearing balls do not cause sleeve axial shifts. The normal force, 


$$
F_{N}=F_{C} \frac{\cos \left(\left(\alpha_{i}+\alpha_{0}\right) / 2\right)}{\cos \left(\left(\alpha_{i}-\alpha_{0}\right) / 2\right)}
$$

The tangential force,

$$
F_{P}=F_{C} \frac{\sin \alpha_{0}}{\cos \left(\left(\alpha_{i}-\alpha_{0}\right) / 2\right)}
$$

The above equations are useful in predicting the moving sleeve positions, which has an influential impact on the location of the rear spindle support and as a result on the location of its tips.

\section{Vibration analysis}

In general, the vibration analysis is normally done in three aspects such as static, modal, and harmonic analysis. The Proe modal of ball bearing is converted into IGS format to import it into the multi-physics software for undergoing finite element analysis, namely ANSYS. The material used is M19 steel has a density of $7600 \mathrm{Kg} / \mathrm{m}^{3}$, Young's modulus as $2 \mathrm{e}^{11}$ $\mathrm{N} / \mathrm{m}^{2}$, and Poisson's ratio as 0.3 . The ball bearing specification is listed in Table 1. The deformation in the $\mathrm{X}$ and $\mathrm{Y}$ direction is shown in Fig 1 and Fig 2.

Table 1: Ball Bearing Specifications

\begin{tabular}{|c|l|c|}
\hline S.no & \multicolumn{1}{|c|}{ Parameters } & Dimensions \\
\hline $\mathbf{1}$ & Inner bore diameter & $25 \mathrm{~mm}$ \\
\hline $\mathbf{2}$ & Outer ring diameter & $52 \mathrm{~mm}$ \\
\hline $\mathbf{3}$ & Pitch diameter & $39 \mathrm{~mm}$ \\
\hline $\mathbf{4}$ & Ball diameter & $7.94 \mathrm{~mm}$ \\
\hline $\mathbf{5}$ & Width & $15 \mathrm{~mm}$ \\
\hline $\mathbf{6}$ & Mass & $0.13 \mathrm{Kg}$ \\
\hline
\end{tabular}

\subsection{Static Analysis}

First, the IGES modal file is imported into the FEA packages. The material assigned to the modal is plane 42 since it is executed in 2D analysis. The static analysis is used to show the displacement of the bearing due to its gravity and its self-weight. Table 2 detailed the displacement due to static conditions in $\mathrm{X}, \mathrm{Y}$ direction, and vector sum.

Table 2: Displacement due to static loading

\begin{tabular}{|c|c|c|c|c|}
\hline $\begin{array}{c}\text { S. } \\
\text { No }\end{array}$ & $\begin{array}{c}\text { Amplitude } \\
(\mathbf{m})\end{array}$ & $\begin{array}{c}\text { X-Direction } \\
\text { displacement }\end{array}$ & $\begin{array}{c}\text { Y-Direction } \\
\text { Displacement }\end{array}$ & $\begin{array}{c}\text { Displacement } \\
\text { Vector Sum }\end{array}$ \\
\hline 1 & Minimum & $-0.207 \mathrm{e}^{-5}$ & 0 & 0 \\
\hline 2 & Maximum & $0.026 \mathrm{e}^{5}$ & $0.414 \mathrm{e}^{-5}$ & $0.416 \mathrm{e}^{-5}$ \\
\hline
\end{tabular}

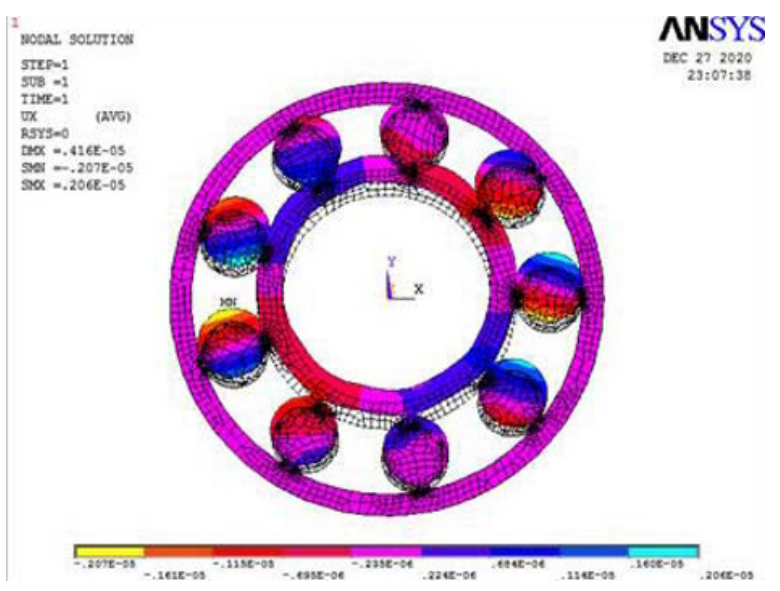

Fig 1: Displacement in $\mathrm{X}$-axis due to gravity

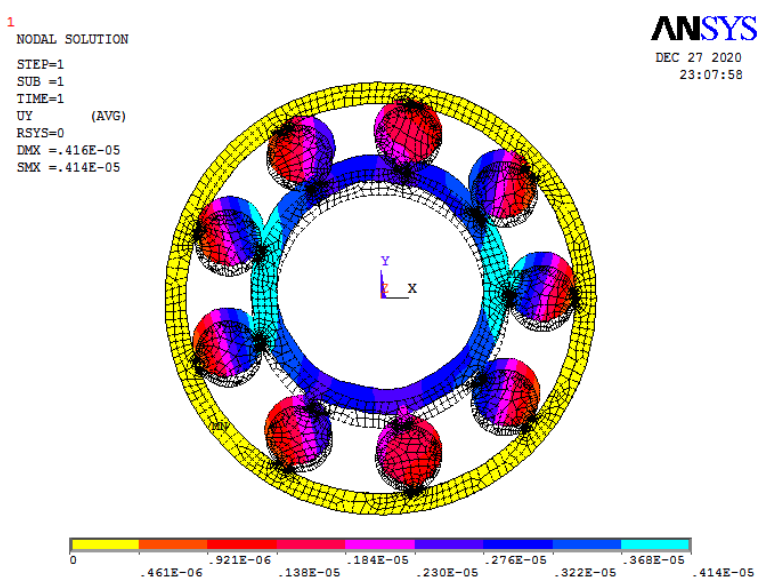

Fig 2: Displacement in $\mathrm{Y}$-axis due to gravity

\subsection{Modal Analysis}

The modal analysis is used to calculate the natural frequency of the bearings. In this analysis, the first five modes' natural frequency is estimated. If in the case during rotation the acoustic noises will be produced, if the vibrating and natural frequency coincides with each other.

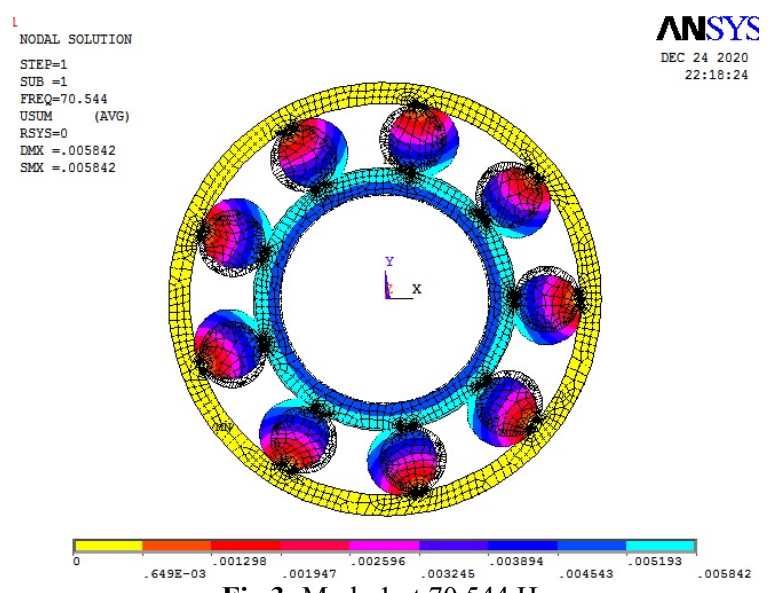

Fig 3: Mode 1 at $70.544 \mathrm{~Hz}$ 


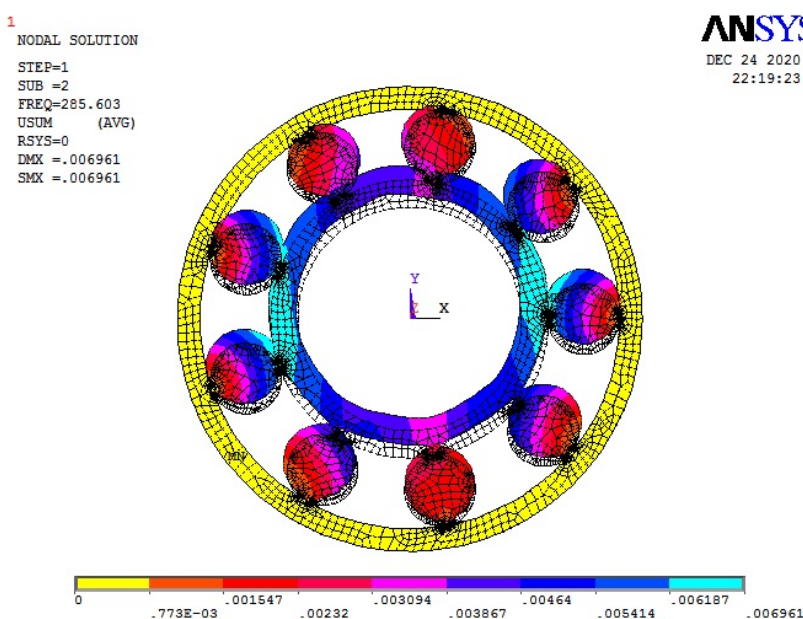

Fig 4: Mode 2 at $285.603 \mathrm{~Hz}$

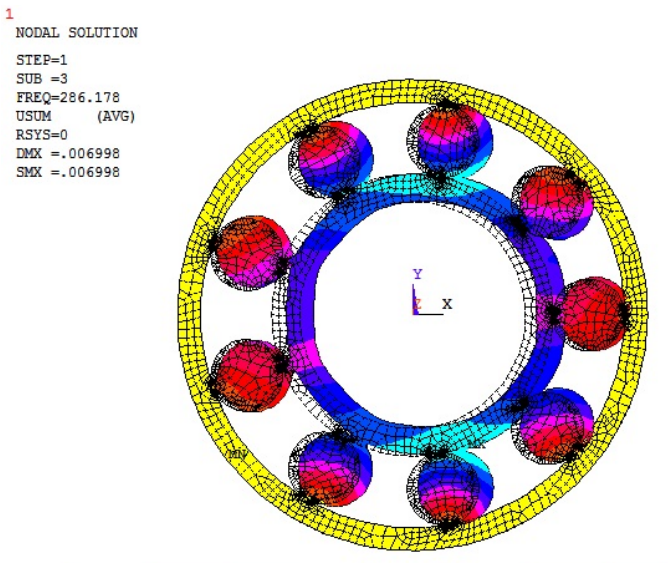

NNSYS

$\mathrm{DEC} 24 \mathrm{2020}$
$22: 20: 08$

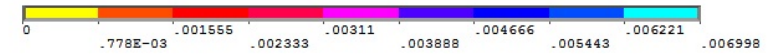

Fig 5: Mode 3 at $286.178 \mathrm{~Hz}$

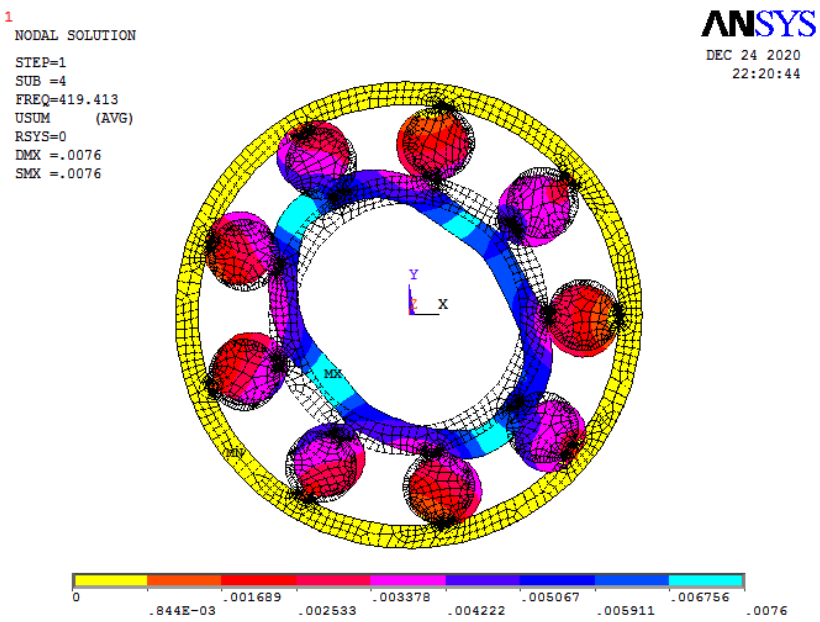

Fig 6: Mode 4 at $419.413 \mathrm{~Hz}$.

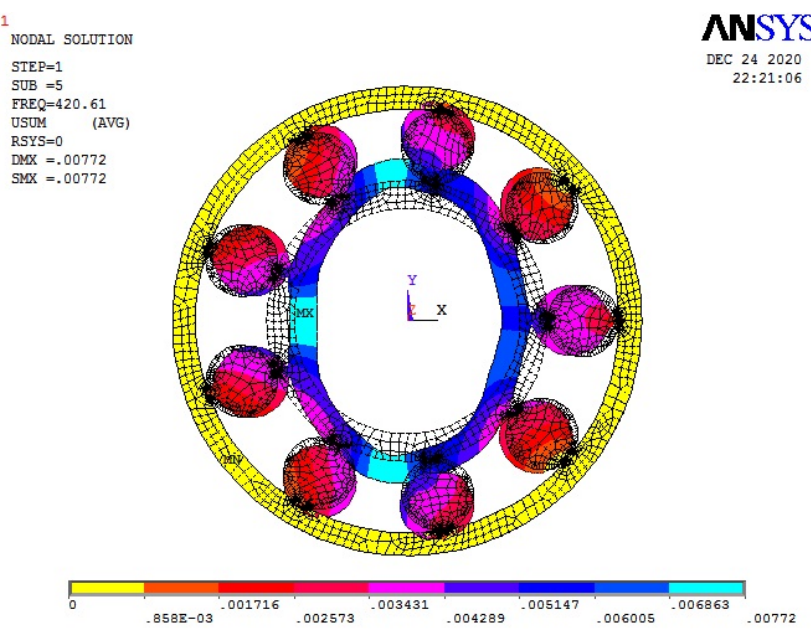

Fig 7: Mode 5 at $420.612 \mathrm{~Hz}$

Table 3: modal frequencies and displacement

\begin{tabular}{|c|c|c|}
\hline Mode & $\begin{array}{c}\text { Frequency } \\
\text { (Hz) }\end{array}$ & $\begin{array}{c}\text { Maximum } \\
\text { Displacement (m) }\end{array}$ \\
\hline 1 & 70.544 & $5.842 \mathrm{e}-3$ \\
\hline 2 & 285.603 & $6.960 \mathrm{e}-3$ \\
\hline 3 & 286.178 & $6.998 \mathrm{e}-3$ \\
\hline 4 & 419.413 & $7.600 \mathrm{e}-3$ \\
\hline 5 & 420.612 & $7.720 \mathrm{e}-3$ \\
\hline
\end{tabular}

Fig 3 to Fig 7 demonstrates the modal frequencies with their corresponding frequencies. From these figures, it is evident that the maximum displacement of the balls increases with applied frequency. The maximum displacements of the balls are resisted to the modular vibrations applied on the balls under different frequency levels. The contours of the various frequency levels and their displacements show the reaction forces that act radially outward direction. Table 3 implies the natural frequency and the corresponding displacement.

\subsection{Harmonic Analysis}

The harmonic analysis is used to estimate the amplitude of vibration by the modal frequencies. The applied force is $100 \mathrm{~N}$.

${ }^{1}{ }_{\text {POST26 }}$ AMPLITUDE
UX_2

NNSYS

$\underset{D E C}{26} 202020$

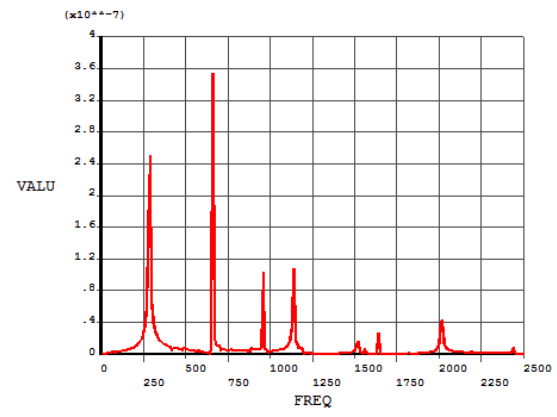

Fig 8: Node 5109 of X-axis at inner race 


$$
\begin{aligned}
& 1 \text { POST26 } \\
& \text { AMPLITUDE } \\
& \text { UY_3 }
\end{aligned}
$$

NNSYS

DEC 262020

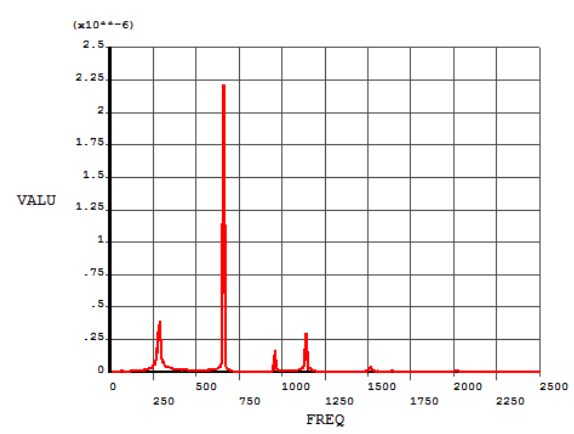

Fig 9: Node 5109 of $\mathrm{Y}$-axis at inner race

The displacements of bearing for $100 \mathrm{~N}$ applied force at 2500 $\mathrm{Hz}$ in the $\mathrm{X}$-axis and $\mathrm{Y}$-axis is shown in Fig. 8 and Fig.9 respectively at the inner race for node 5109 .

$$
\begin{aligned}
& 1 \text { POST26 } \\
& \text { AMPLITUDE } \\
& \text { UX_4 }
\end{aligned}
$$

ANSYS

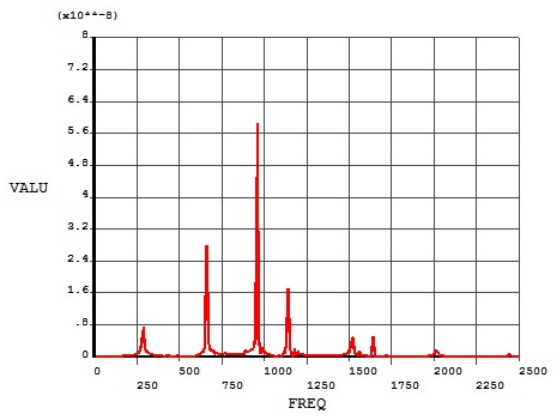

Fig 10: Node 966 of $\mathrm{X}$-axis at outer race

$$
\begin{aligned}
& 1 \\
& \text { POST26 } \\
& \text { AMPLITUDE } \\
& \text { UY_5 }
\end{aligned}
$$

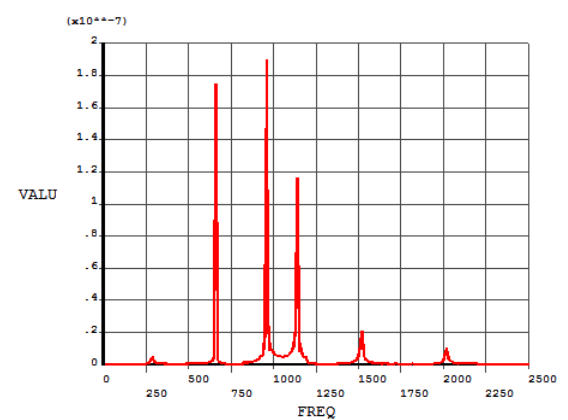

Fig 11: Node 966 of Y-axis at outer race

Fig 10 and Fig 11 are used to understand the amplitude displacement for the outer race (Node 966). It is obvious that for the $700 \mathrm{~Hz}$ frequency loading, the $\mathrm{X}$ axis inner race shows higher displacement amplitude than the $\mathrm{Y}$ axis of bearing 5109 node. But for the $900 \mathrm{~Hz}$ frequency loading, the $\mathrm{Y}$ axis outer race shows higher displacement amplitude than the $\mathrm{X}$ axis of bearing 966 node. This is because of the unbalanced of rotating elements (cage balls or rollers).
Table 4 shows the $\mathrm{X}$-axis and $\mathrm{Y}$-axis displacement variation for various frequencies of node 5109 and 966 nodes respectively.

Table 4: Harmonic analysis displacement and frequency

\begin{tabular}{|c|c|c|c|c|}
\hline $\begin{array}{c}\text { S. } \\
\text { No }\end{array}$ & Node & Axis & $\begin{array}{c}\text { Displacement } \\
\text { (m) }\end{array}$ & $\begin{array}{c}\text { Frequency } \\
\text { (Hz) }\end{array}$ \\
\hline $\mathbf{1}$ & $\begin{array}{c}5109 \\
\text { (Inner Race) }\end{array}$ & $\mathrm{X}$ & $3.60 \mathrm{e}-7$ & 700 \\
\hline $\mathbf{2}$ & $\begin{array}{c}5109 \\
\text { (Inner Race) }\end{array}$ & $\mathrm{Y}$ & $0.23 \mathrm{e}-7$ & 700 \\
\hline $\mathbf{3}$ & $\begin{array}{c}966 \\
\text { (Outer Race) }\end{array}$ & $\mathrm{X}$ & $0.60 \mathrm{e}-7$ & 900 \\
\hline $\mathbf{4}$ & $\begin{array}{c}966 \\
\text { (Outer Race) }\end{array}$ & $\mathrm{Y}$ & $1.90 \mathrm{e}-7$ & 900 \\
\hline
\end{tabular}

\section{Conclusion}

As a method for assisting predictive and preventive maintenance, vibration analysis is becoming incredibly influential. Both time domain and frequency domain vibration analyses may provide valuable information when tracking rolling element bearings. The vibration analysis in the time domain will reveal whether a bearing is operating abnormally and display the amplitude increase trend. Vibration analysis in the frequency domain may determine if the enhanced vibrations are caused by a specific bearing defect or by external causes. The increase in vibration energy on the bearing's characteristic frequencies may also signify the progress of that particular fault.

In this present research, the vibration analyses of Single Row SKF6205 Deep Groove Ball Bearing are investigated. To obtain the noiseless motion in its applications, various analyses are performed. The static analysis in Table 2 shows the displacement vector sum of the bearing due to its gravity and its self-weight. The simulation results from Fig 1 and Fig 11 , show the $\mathrm{X}$-axis and $\mathrm{Y}$-axis deformations in different modes. The modal analysis is performed for five modes the natural frequency of the bearings. Acoustic noises are generated by the bearings during rotation when the vibrating and natural frequencies correspond to each other. By the harmonic analysis, with the applied force of $100 \mathrm{~N}$, the amplitude of the vibration of the nodes showed that the outer race has less displacement than the inner race.

\section{References}

1. S.H. Ghafari, E.M. Abdel-Rahman, F. Golnaraghi, F. Ismail, Journal of Sound and Vibration, 329(9), 1332 (2010)

2. D. Koulocheris, A. Stathis, T. Costopoulos, D. Tsantiotis, Engineering Failure Analysis, 39, 164 (2014)

3. R.K. Sreenilayam-Raveendran, M.H. Azarian, C. Morillo, M.G. Pecht, K. Kida, E.C. Santos, T. Honda, H. Koike, Wear, 302(1-2), 1499 (2013) 
4. P. Göncz, J. Flašker, and S. Glodež, Procedia Engineering, 2(1), 1877 (2010)

5. O. Halminen, A. Kärkkäinen, J. Sopanen, A. Mikkola, Mechanical Systems and Signal Processing, 50, 692 (2015)

6. T. Karacay, N. Akturk, Tribology International, 42(6), 836-(2009)

7. J. Jedrzejewski, W. Kwasny, CIRP annals, 59(1), 377 (2010)

8. G.K. Nikas, Proceedings of the Institution of Mechanical Engineers, Part J: Journal of Engineering Tribology, 224(5), 453 (2010)

9. M.M. Maru, R.S. Castillo, L.R. Padovese, Tribology International, 40(3), 433 (2007)

10. S. Padmanabhan, S.Thiagarajan, A.D.R. Kumar, D. Prabhakaran, M. Raju, Materials Today: Proceedings, 44, 3550 (2021)

11. R.S. Dwyer-Joyce, Wear, 233, 692 (1999) 